\author{
Maria Bernardete Ramos Flores \\ Universidade Federal de Santa Catarina
}

\title{
Androginia e Surrealismo a propósito de Frida e Ismael - velhos mitos: eterno feminino
}

Resumo: Nas primeiras décadas do século XX, retorna o mito do Andrógino como promessa de felicidade espiritual. Entre os surrealistas, a androginia junto ao culto da mulher funcionou como alteridade, como valorização dos subterrâneos da modernidade. A androginia aparece em vários trabalhos de Frida Kahlo no México e Ismael Nery no Brasil, ambos com aproximação ao Surrealismo. Em Frida, o mito oscila entre espiritual e político, entre transgressão e sujeição, vai do lesbianismo e do desejo de inversão dos tradicionais papéis de gênero à dissolução de sua própria identidade, submetida no amor pelo marido. Ismael, na duplicidade de seus autorretratos e na iconografia dos casais amorosos, expressa a fusão dos sexos como parte do mundo das ideias. "Sexo artístico por excelência", os mitos aparecem com maior força na arte de Ismael Nery.

Palovras-chave: androginia; Surrealismo; Frida Kahlo; Ismael Nery.

Copyright (๑) 2014 by Revista Estudos Feministas.
Diego:

Nada comparable a tus manos Ni nada igual al oro-verde de Tus ojos. Mi cuerpo se llena De ti por dias y dias. Eres El espejo de la noche. La luz violeta del relâmpago. La humedad de la tierra. EI hueco de tus axilas es mi refugio.
Eu

Eu sou a tangência de duas formas opostas e justapostas Eu sou o que não existe entre o que existe

Eu sou tudo sem ser coisa alguma Eu sou o amor entre os esposos Eu sou o marido e a mulher Eu sou a unidade infinita

\section{O bigode de Zapata}

\footnotetext{
' Para visualizar a reprodução do
quadro visite a página: http://juan

' Para visualizar a reprodução do
quadro visite a página: http://juan carlosboverimuseos.wordpress.com/ category/pinturas-del-museo-dearte-moderno-de-nueva-york/
}

No quadro Cortándome el pelo com unas tijeritas, também conhecido como Autorretato de pelona (1940), ' Frida Kahlo (1907-1954) aparece de cabelos cortados, trajando um terno masculino, de tonalidade escura; nas mãos, a 
${ }^{2}$ Hayden HERRERA, 2011 , p. 367.

${ }^{3}$ Patricia MAYAYO, 2008.

${ }^{4}$ MAYAYO, 2008, p. 228-253.

${ }^{5}$ MAYAYO, 2008, p. 230.

${ }^{6}$ MAYAYO, 2008, p. 236. tesoura que usara para cortar a longa e espessa cabeleira; no chão, as mechas negras preenchem o fundo do quadro formando um espaço sinistro; o único signo de feminilidade que lhe resta são os brincos ainda pendurados nas orelhas; um tufo de cabelo está pendurado entre as pernas, como um animal abatido, e ela segura a tesoura junto aos genitais, o que nos induz a pensar que uma parte de si, capaz de amar, fora extirpada. No alto do quadro, um verso de uma antiga canção popular: "Mira que si te quise, fue por el pelo. Ahora que estás pelona, ya no te quiero". O quadro, realizado pouco depois de seu divórcio, representaria, segundo Hayden Herreira, o desespero da artista, um ato de vingança, destruindo um atributo de sexualidade feminina que tanto agradava a Diego Rivera. Frida cria uma imagem de "ira e sexualidade ofendida". ${ }^{2}$ Herrera atribui, portanto, ao quadro um significado biográfico, tal como outros estudos a respeito da artista mexicana que procuram refletir sobre suas dores desde o fatídico acidente, aos 18 anos, e sobre sua relação tumultuada com Diego Rivera.

Porém, como mostra Patricia Mayayo, ${ }^{3}$ outras abordagens apontam para uma dimensão mais política para refletir sobre o gosto de Frida em se representar, em fotos e autorretratos, com trajes que misturam atributos masculinos (camisa de corte masculino e calça comprida) e femininos (nos adereços, como em brincos, colares e sapatos, além do penteado). São famosos seus autorretratos de grande beleza nos trajes femininos, suas longas saias bordadas, el traje de tehuana oficial, exuberância no penteado e nas joias, mas com um rosto de traço masculino, de enormes sobrancelhas e espesso bigode. ${ }^{4}$ Neste caso, faz-se conexões entre o Autorretato de pelona, em que Frida está de terno e cabelo curto, e a imagem da 'Nova Mulher' dos anos vinte e trinta; embora no México não se tenham presenciado mudanças significativas na situação feminina, a imagem da mulher moderna chega ao país através de revistas norte-americanas e do cinema. ${ }^{5}$

O tão grande interesse de Frida, portanto, pelo travestismo pode estar relacionado ao questionamento das noções sobre a feminilidade na época e também à sua própria bissexualidade. Mayayo lembra que se pode pensar que a homossexualidade de Frida fosse uma forma de submissão a Diego, já que, por causa de seus problemas físicos, ela pouco teria contato com o sexo oposto, ainda mais que de preferência se relacionava com as mesmas mulheres com as quais o marido se relacionava. Porém, a partir de fotos de Kahlo anteriores às suas primeiras experiências lésbicas essas por volta dos treze anos - vê-se que sua ambiguidade sexual é clara, usada na construção de uma identidade, pouco convencional para a época. ${ }^{6}$ Herrera, por sua vez, informa que Diego falava abertamente da virilidade de sua

816 Estudos Feministas, Florianópolis, 22(3): 815-837, setembro-dezembro/2014 
${ }^{7}$ HERRERA, 2011 , p. 468.

${ }^{8}$ Para visualizar uma reprodução do quadro, visite a página: http:// www.frida-kahlo-foundation.org/ the-complete-works-2-48-3-0.html

${ }^{9}$ HERRERA, 2011 , p. 460 .

10 MAYAYO, 2008, p. 246.

1 MAYAYO, 2008, p. 250.

12 MAYAYO, 2008, p. 249.

${ }^{13}$ Para visualizar uma reprodução do quadro, acesse: $<$ http://www. itaucultural.org.br/aplicexternas/ enciclopedia_IC/Enc_Obras/ dsp dados obra.cfm?cd obra $=1$ $354 \&$ cd_idioma $=28555 \&$ cd_verbe $=900 \&$ num_obra $=3>$. esposa e que lhe encantavam seus modos masculinos e seu bigode de Zapata. $^{7}$ A fascinação de Frida pelo tema da androginia fez com que ela não só se representasse com uma mistura entre atributos femininos e masculinos, mas também ao marido. Nos desenhos de 1932, em colaboração com Luciene Bloch, chamados Cadáver exquisito, numa técnica surrealista, Frida se apropria do pênis, enquanto Diego Rivera, com seios e sapatos altos, segura uma vassoura, símbolo do trabalho doméstico.

Ainda, um tipo de androginia mística deve ter servido de inspiração para o quadro Retrato doble de Diego y yo 1929-1944 (1944). ${ }^{8}$ No quadro, um rosto dividido verticalmente em duas metades: Diego Rivera à esquerda e Frida Kahlo à direita, unidos por um colar feito de galhos de árvore trançados. O amor entre os esposos se apresenta, assim, como uma fusão carnal e espiritual. Suas personalidades se fundem no todo que antecedeu a presumível união original que aparece em várias cosmogonias. À direita do quadro, a presença do sol e da lua alude aos dois princípios: masculino e feminino. Abaixo, uma vieira e uma concha simbolizam a união entre os sexos, conforme propõe Herrera. ${ }^{9}$

Nesse caso, a inspiração de Frida pelo andrógino como conciliação dos contrários parece ter vindo da mitologia asteca. O rosto dividido, característico do pensamento mexicano, é considerado como uma manifestação de "dualidad cósmica y creativa, los elementos femeninos y masculinos unidos en un tipo de hermafroditismo, lo bueno y lo malo que provienen de la misma fuente". ${ }^{10}$ Kahlo representa sua relação amorosa com Diego a partir dos anos quarenta como um retorno à origem "uma restauración de la androginia primordial". " Assim, o Retrato doble de Diego y yo conecta a fusão amorosa com o ideal de coincidentia oppositorum presente na tradição précolombiana e também oriental, já que Frida tinha grande interesse pelo hinduísmo, religiões e filosofias orientais. Em seu diário, há vários desenhos da mandala chinêsa yin yang, que representa a conciliação entre os opostos. O símbolo, por vezes, encontra-se junto de figuras andróginas, em outras, está associada à palavra 'sadja', que pode ser interpretada a partir de 'sadha', que significa céu e terra, ou a partir de sahaja, unidade na interpretação dos amantes. ${ }^{12}$

\section{Sexo artístico por excelência}

Menos conhecido que Frida Kahlo, encontramos Ismael Nery (1900-1934) no Brasil, artista místico que aludiu reiteradamente em forma pictórica e poética a imagem da androginia ou da fusão entre os sexos. No quadro Andrógino, ${ }^{13}$ uma linha vertical divide o rosto da figura. A metade 
14 Joséphin PÉLADAN, 2011, p. 109. "O andrógino nos transporto para fora do tempo e do espaço, longe das paixões, no reino dos arquétipos, o mais alto que pode atingir o nosso pensamento." (Tradução nossa)

${ }^{15}$ Ismael NERY, 2000, p. 66. masculina joga com a fisionomia dos seus autorretratos; a outra metade lembra o de Adalgisa, sua esposa, de forma semelhante ao Retrato doble de Diego y yo de Frida. Contudo, se no quadro da artista mexicana percebe-se a fragilidade do vínculo matrimonial (as duas partes não estão bem soldadas) e a ânsia de Frida para reatar-se ao marido (ela passara o ano de 1944 separada de Diego), o Andrógino de Ismael apresenta-se como uma misteriosa unidade a se completar. A linha que cola as duas metades dá a entender que a 'sutura' forma uma dobra que se caminha para uma fusão total entre o masculino e o feminino, para uma imagem sintética a ser alcançada. Parece que esta é a tônica imagética em toda a obra de Ismael, a androginia sugerida nunca chega à realização. Nas obras de Ismael, o andrógino só é resolvido como "sexo artístico por excelência", fórmula que Joséphin Péladan usa para dizer que 'I' androgino ci transporta fuori del tempo e delle spazio, lontano dalle passioni, nel dominio degli archetipi, il più alto che possa raggiungere il nostro pensiero."14

Se no conjunto a obra de Frida Kahlo é mais narrativa, mais autobiográfica - sendo inclusive a androginia mais conectada com suas experiências -, a obra de lsmael é mais alegórica, e a androginia que aparece em sua pintura é mais relacionada aos seus princípios filosóficos e espirituais. Seu principal motivo era o corpo humano, em retratos, casais e triangulações, tomando a si e a esposa, como modelos, mas suas figuras não são representações de personagens ou de situações autobiográficas. Apenas na sua última fase, a partir de 1930, acometido pela tuberculose, deparamo-nos com uma arte que expressa seu desespero diante da morte iminente e, então, pode-se pensar numa arte biográfica. Ismael "considerava-se muito mais um pensador que um pintor e, por isso, recorria ao pincel para expressar quando não o fazia com a caneta". 15

Se Frida dilacera seu corpo, apresenta-o em diversas situações, procura certo grau de realismo sem jamais abandonar o acento de suas formas expressivas, necessitando do espelho para encontrar os elementos que conferem sua mudança de ânimo em relação a situações biográficas, Ismael, nos seus autorretratos, desdobra-se em vários eus, multiplica-se, duplica-se, faceta-se em divino e satânico, em masculino e feminino, em místico e erótico, se sobrepõe ou se funde com Adalgisa, a esposa, ou com o amigo, o poeta Murilo Mendes, aparecendo em personagens diferentes, às vezes até irreconciliáveis. Seus traços fisionômicos - o nariz aquilino que se liga à curva da sobrancelha, os olhos rasgados, o pescoço longilíneo, o cabelo em ponta como o das melindrosas da época, o rosto oval em meio perfil -, além do enquadramento, mostrando a figura do busto para cima,

818 Estudos Feministas, Florianópolis, 22(3): 815-837, setembro-dezembro/2014 
${ }^{16}$ Luiz A. S. MUNARI, 1984, p. 43.

17 Para visualizar os autorretratos Cristo (1923), Auto-retrato (1925), Auto-retrato (1925), acesse: $<$ http://www.revistaescarlate.com/ 1/post/2009/10/atravs-do-espelhoguimares-rosa.html> ou <http:// www.itaucultural.org.br/aplicexter nas/enciclopedia_IC/index.cfm?fu seaction $=$ artistas_obras\&acao $=\mathrm{ma}$ is\&inicio $=33 \&$ cont_acao $=5 \& \mathrm{~cd}$ _ver bete $=900>$.

\footnotetext{
${ }^{18}$ Sérgio MICELI, 1996, p. 78.

${ }^{19}$ Para visualizar os casais de Ismael Nery acesse: <http://www.itaucultu ral.org.br/aplicexternas/enciclope dia_IC/index.cfm?fuseaction $=$ arti stas_obras\&acao $=$ mais\&inicio $=3$ $3 \& c 0 n t$ acao $=5 \& c d$ verbete $=900>$.
}

$20 \mathrm{O}$ historiador de arte Tadeu Chiarelli (citado por NERY, 2004, p. 186) supõe que, entre os coetâneos, locais e internacionais, a única obra no Brasil que se possa emparelhar com a de Ismael seja a de Frida Kahlo. formam os "estilemas" de Ismael, ${ }^{16}$ por aparecerem não só nos seus autorretratos, mas reproduzidos em várias de suas figuras, inclusive, femininas. ${ }^{17}$

$\mathrm{Se}$, em alguns autorretratos, Ismael pinta-se como personagem de masculinidade até exacerbada, em outros, mesmo de aparência masculina definida, o cabelo é à la garçonne, curto como o das melindrosas da época, e muito semelhante a vários penteados em retratos de Adalgisa. No Andrógeno, que vimos acima, há uma edição feminina colada ao seu ser masculino. O cabelo comprido do lado masculino se sobrepõe e se dilui por sobre o lado feminino, integrando-se. No pequeno Auto-retrato (1925), o artista aparece com uma blusa russa. A mão direita espalmada no peito exibe um anel redondo, os dedos longos, as unhas pintadas. A boca é desenhada com batom, os olhos rasgados, os cabelos armados num caimento em ponta. Nas palavras de Sérgio Miceli, "um homem fantasiado de mulher, figura híbrida, ente misterioso, com elementos extraídos de suas aparições masculinas e de suas projeções femininas". ${ }^{18}$ No Autorretrato-Cristo, Ismael sobrepõe suas feições numa representação andrógina de Cristo.

Nas obras em que configura 'o par amoroso', ${ }^{19}$ as duas figuras fundem-se num abraço que embaralha as personagens, em faturas pouco definidoras dos sexos, como se nessas obras, de dualidade explícita, se voltasse à dualidade dos retratos. Em Duas amigas, por exemplo, uma das figuras repete Adalgisa dos vários retratos e a outra é o próprio Ismael. Na verdade, mais uma vez, a maioria dos casais repetem os traços de Ismael e de Adalgisa, ou, mais frequentemente, tanto nas figuras aos pares quanto nos quadros de 'trios' ou de mais figuras, os rostos repetem os 'estilemas' do artista, presentes nos quadros de uma só figura.

A partir daqui, faremos uma digressão para buscar as ressonâncias do retorno do mito do andrógino, que ocorrera nas primeiras décadas do século XX, na obra dos dois artistas, Frida no México e Ismael no Brasil. Ao final, veremos que, apesar das aproximações entre um e outro, ${ }^{20} \mathrm{O}$ uso do mito do andrógino teve propósitos diferentes, relacionados às posturas pessoais diante da vida e, especialmente, da arte. Em Frida, o mito oscila entre espiritual e político, entre transgressão e sujeição, vai do lesbianismo e do desejo de inversão dos tradicionais papéis de gênero à dissolução de sua própria identidade, submetida no amor pelo marido. Ismael, na duplicidade de seus autorretratos e na iconografia dos casais amorosos, expressa a fusão dos sexos como parte do mundo das ideias. "Sexo artístico por excelência", os mitos aparecem com maior força na arte de Ismael Nery. 


\section{A androginia na imaginação moderna}

${ }^{21}$ Fernando PESSOA, p. 76.

${ }^{22}$ Citado por: MAYAYO, 2008, $\mathrm{p}$ 231.

${ }^{23}$ Symonds ADDINGTON, 1891, p.

1256 e seguintes.

${ }^{24}$ Edward CARPENTER, 2007.

${ }^{25}$ Edward WESTERMARCK, 2006.

${ }^{26}$ Lisa RADO, 2000.

${ }^{27}$ Essa problemática foi tema de minhas pesquisas anteriores (Maria Bernardete Ramos FLORES, 2007).

${ }^{28}$ Cf. Francisco V. GARCÍA, 1999, p. 232.

\author{
Inventemos um Imperialismo Andrógino reunindo as \\ qualidades masculinas e femininas; um imperialismo \\ alimentado de todas as sutilezas femininas e de todas as \\ forças de estruturação masculinas. Realizemos Apolo \\ espiritualmente. ${ }^{21}$
}

No começo do século XX, retornara o fantasma do andrógino como promessa de felicidade, no meio das artes, em ressonância com uma literatura médico-científica, que insurgiu-se para discutir o assunto da homossexualidade em novas e positivas imagens. Magnus Hirschfeld, famoso médico sexólogo, militante na defesa dos homossexuais e líder do movimento que pediu a revogação do parágrafo 175 da lei alemã que penalizava as relações homossexuais, publicara em 1904 Berlins Dritles Geschlecht (1904), desenvolvendo a teoria do terceiro sexo. ${ }^{22}$ Addington Symonds considerou que os conceitos da medicina legal, patologizando o amor entre pessoas do mesmo sexo, causara terrorismo e inferno à vida do homossexual. A discussão sobre os 'viris amores' dos poemas de Walt Whitman levara o autor a especular sobre um futuro melhor para as paixões mútuas dos homens. ${ }^{23}$ Edward Carpenter ${ }^{24}$ e Edward A. Westermarck ${ }^{25}$ defenderam a ideia de que os urânios eram dotados de superior inteligência, criatividade e força visionária. Poderiam ser diferentes, mas não malucos. Carpenter lembrou que era de artistas a maioria dos casos de 'homens invertidos', estudada por Ellis e Krafft-Ebing, avetando, em 1907, que os urânios se tornariam a primeira encarnação da utopia modernista da vanguarda. ${ }^{26}$

Em síntese, essa nova literatura médico-científica, ao tratar o homossexual como um ser superior, espiritualizado, dotado de potências criadoras, contrariava as noções de patologia da homossexualidade, sob os pressupostos das teorias da degeneração racial. ${ }^{27}$ Krafft-Ebing e seus seguidores, a despeito de diferenças entre suas teorias, haviam sido ferrenhos na luta para pintar 'o sexo intermediário' como uma figura desagradável, noção que, de alguma forma, fazia ressonância com a fatura artística dos decadentistas de fin de siècle em coro com todo um elenco de angústias, que vai de Schopenhauer, Schereber, Weininger a Freud, os quais viam na identidade sexual um peso exigido pela civilização. Afirmara-se que a criança, ab initio um 'perverso polimorfo', somente alcançaria a plena diferença sexual através de um processo doloroso, marcado pela repressão, gratificação imediata e internalização das normas sociais. Esse processo, que atravessa etapas sucessivas, descritas por Freud em 1905, é o que conduz finalmente à localização genital e heterossexual da libido. ${ }^{28}$ Na versão de Weininger, a diferenciação sexual nunca chega a completarse de todo: os seres humanos são sempre uma combinação

820 Estudos Feministas, Florianópolis, 22(3): 815-837, setembro-dezembro/2014 
29 Otto WEININGER, 1975, p. 162. 30 O Andrógino, na mitologia Ocidental, seria o homem primordial, visto como estado de perfeição e completude. Difere do Hermafrodito, mais ligado à homossexualidade, visto como uma figura ambígua, diminuída no seu Ser. Ambas as posturas (nostalgia pela perfeição e perda da quantidade de Ser) oscilam na reativação de ambos os mitos, em vários momentos da história. Para uma genealogia do hermafroditismo ver GARCÍA, 1999

${ }^{31}$ PLATÃO, 1997, p. 125-126.

32 Mircea ELIADE, 1999, p. 103105. variável de traços masculinos e femininos, de modo que a intersexualidade é sua condição natural. No fin de siècle, vivia-se uma crise por haver uma predominância da feminilidade que afetava os homens. ${ }^{29}$

O termo "androginia", ${ }^{30}$ até onde se tem notícia, foi empregado pela primeira vez em O Banquete de Platão. Segundo o mito, na voz do comediógrafo Aristófanes, havia, a princípio, três espécies de homens, e não duas. O terceiro gênero chamava-se Andróginos, porque, devido seu aspecto e nome, lembravam o macho e a fêmea. Eles não foram felizes para sempre, uma vez que, ao escalarem o Olimpo para fazerem guerra aos deuses, receberam de Zeus cruel castigo: através de um raio, foram cortados ao meio e separados irreversivelmente. A partir disso, deveriam passar o resto da eternidade à procura de sua metade perdida. ${ }^{31}$ É complexa, densa e extensa a doutrina do andrógino, segundo Mircea Eliade. O tema é encontrado na Torá, em seitas gnósticas cristãs, nas doutrinas neoplatônicas e neopitagóricas e em doutrinas orientais. São Paulo e o Evangelho de João incluíram a androginia entre as características da perfeição espiritual. Entre os teósofos neoplatônicos e neopitagóricos e entre os hermetistas, que invocam o Pimandro de Hermes Trismegistro, ou entre os numerosos gnósticos cristãos, a perfeição humana era imaginada como uma unidade sem fissuras. Na ideia de bissexualidade universal, como consequência da bissexualidade divina, enquanto modelo e princípio de toda existência, encontra-se a ideia de que a perfeição consiste numa unidade-totalidade. Tudo o que é por excelência deve ser total, comportando a coincidentia oppositorum em todos os níveis e em todos os contextos. Isto se verifica tanto na androginia dos deuses quanto nos ritos da androginização simbólica, e igualmente nas cosmogonias da origem do mundo a partir de um ovo ou de uma totalidade primordial em forma de esfera. ${ }^{32}$

No Renascimento, entre os alquimistas, aparece a imagem do andrógino primordial; na tradição cabalística, a perda da androginia é o paradigma de toda a nostalgia e só poderá ser restaurada pela reintegração da harmonia original; para o místico luterano Boehme, Adão era um ser andrógino, e o aparecimento dos sexos teria sido uma consequência direta da queda; para Swedenborg, o andrógino, semelhante aos anjos, fora no começo e será de novo no fim dos tempos, ou seja, o homem voltará a ser andrógino. Entre os românticos alemães, que trabalharam com o tema do homem primordial, o andrógino seria o tipo de homem perfeito do futuro. Ritter (médico, amigos do poeta Novalis) dizia que o homem do futuro seria andrógino, como Cristo. Eva teria sido engendrada pelo homem sem a ajuda da mulher; Cristo, pela mulher sem a ajuda do homem; o Andrógino nascerá 
${ }^{33}$ Cf. Jean LIBIS, 2001, p. 82-84.

${ }^{34}$ GARCÍA, 1999, p. 234. dos dois. $O$ crescimento espiritual se daria pela unidade completa entre o esposo e a esposa. Ao descrever a nova humanidade, Ritter utiliza a terminologia alquímica, indícios de que a alquimia era uma das fontes dos românticos em sua (re)atualização do mito do andrógino. Wilhelm Von Humboldt tratou do mesmo assunto. Friedrich Schlegel abordou o ideal do andrógino, criticando a acentuação dos caracteres exclusivamente masculinos ou femininos a que se chega pela educação e pelos costumes modernos, pois, escrevia ele, a finalidade para a qual deve tender a espécie humana é a reintegração progressiva dos sexos até a obtenção da androginia. Para Fraz Von Baader, o andrógino "[...] no designa ni una simple ausencia de sexo ni un hermafroditismo, sino que constituye una síntesis original de los principios activo y pasivo". ${ }^{33}$

Na França, em Serafita (1835), Balzac ilustrara as doutrinas de Swedenborg sobre o andrógino como homem perfeito. Théophile Gautier, em Mademoiselle de Maupin (1835), conta a história de uma jovem que decide passar-se por homem. De beleza extraordinária, seduz a homens e mulheres, igualmente.

Porém, se os andróginos do Romantismo aparecem com suas alegorias otimistas de fraternidade e reconciliação, os artistas prerrafaelitas, simbolistas e decadentistas, por sua vez, multiplicaram a presença do andrógino com aspectos um tanto sombrios. Como ginandro, temos o caso da femme fatale, a mulher devoradora, como a Salomé de Wilde, ilustrada por Beardsley. As ninfas e sirenas de fin de siècle repetem estereótipos femininos associados ao debilitamento, à consumissão da virilidade e à malignidade, o que pode ser uma expressão que tenta romper com a ordem burguesa, mas também símbolo de um novo terror masculino ante a presença rebelde da mulher. Sob outro aspecto, temos a figura do adolescente virginal, $\mathrm{O}$ andrógino com aparência de efebo, nem homem nem mulher. Nesse caso, alude-se diretamente a uma experiência da homossexualidade como transgressão e como imagem da eterna juventude. No campo pictórico, a imagem é projetada nas figuras lânguidas e evanescentes dos prerrafaelitas (Rosetti, Salomon, BurneJones) e simbolistas (de Gustave Moureau a Gustav Klimt). ${ }^{34}$

Em síntese, o tema do andrógino, no último quartel do século XIX, aparece circundado por duas perspectivas: a) patologizado, no contexto da medicalização do sexo; e b) como tema de angústia da literatura decadentista que trata de um andrógino atormentado pela falta de identidade, um hermafroditismo mórbido com a perda de seu simbolismo cósmico, já que não seria mais aquele tipo de homem perfeito, purificador das origens e promessa de humanidade espiritualizada, que aparecera no Romantismo da primeira metade 
${ }^{35}$ Joris-Karl HUYSMANS, $2011, \mathrm{p}$. 169-170.

${ }^{36}$ Albert BÉGUIN, 1938, p. 10-13

${ }^{37}$ ELIADE, 1999, p. 101

${ }^{38}$ Xavière GUTHIER, 1971.

do século XIX. Em L'Androgyne de Josephin Péladan (1891), oitavo tomo de uma série de romances intitulados La décadence latine, o andrógino é compreendido unicamente como um hermafrodita no qual os dois sexos coexistem anatomicamente e fisiologicamente. Trata-se não de uma plenitude de vida à fusão dos sexos, mas de uma superabundância de possibilidades eróticas. Em Às avessas (Às rebours), de Huysmans, uma espécie de bíblia dos decadentistas, Miss Urânia, "uma americana de corpo bem-feito, de pernas nervosas, músculos de aço, braços de ferro", avizinhava-se do "andrógino". Dotada de "encantos ágeis e vigorosos de um macho", diante da qual o protagonista des Esseintes sentese "afeminar-se" debilmente, e com quem deseja trocar de papel sexual numa relação amorosa, sonho frustrado, porque não existia, no corpo da parceira cobiçada às avessas, "a transmutação das ideias masculinas". ${ }^{35}$

Assim, no começo do século XX, no retorno de uma imagem mais positiva da androginia, não só uma nova literatura médica discutiu a questão legal, ética e fisiológica da homossexualidade. A arte, especialmente entre os surrealistas, ressuscitou a imagem milenar do andrógino como 'homem primordial' que existira no começo do mundo. Em 1938 foi publicado na revista surrealista Minotaure o artigo de Albert Béguin ${ }^{36}$ intitulado L'androgyne, abordando o mito do andrógino desde os gregos, passando por Boehme, pelos românticos alemães, até Serafita de Balzac, romance que Eliade considera a última grande criação literária europeia a dar brilho à imagem do andrógino, como imagem exemplar de homem perfeito, tal como é tratado pela antropológica arcaica. ${ }^{37}$ Xavière Guthier mostra como em Breton, Eluard e Aragon o vocabulário amoroso sacraliza seu objeto, reiterando o mito cortês da mulher. ${ }^{38}$ Isso aparecia já claramente na literatura romântica, mas a mulher romântica segue estando associada a uma escatologia teológico-religiosa. A mulher, na perspectiva dos surrealistas, é promovida a uma dignidade de ser, em termos frequentemente exaltados que fazem dela uma espécie de mediação entre o mundo e o homem. Ao fazê-lo, o discurso erótico do poeta tem vocação cósmica ao mesmo tempo em que aponta para a restauração andrógina.

\section{A potência do feminino}


${ }^{40}$ ARAGON, 1996, p. 194.

${ }^{41}$ BRETON, 1999, p. 105.

42 BRETON, 1971, p. 99.

${ }^{43}$ Alquié FER, 1998, p. 171.

${ }^{44}$ André BRETON, 1986, p. 23.

${ }^{45}$ BRETON, 1971, p. 99.

46 BRETON, p. 104.
O culto à mulher foi uma das principais marcas do Surrealismo. No romance O Camponês de Paris, de Aragon, publicado em 1926, a mulher toma o lugar de todas as formas. ${ }^{40} \mathrm{Em}$ Nadja, de Breton, publicado em 1928, a mulher era "um gênio livre, algo como um desses espíritos do ar que certas práticas mágicas permitem momentaneamente prender-se a alguma coisa, mas aos quais não seria possível submeter-se". ${ }^{41}$ Em Amor Louco, de 1937, Breton fala de sua personagem: "Um dia virá em que o homem saberá reconhecer-te como seu único senhor e prestar-te honras até mesmo nas misteriosas perversões em que o envolves." ${ }^{42}$ Para Breton, as ideias das mulheres se afirmariam em detrimento das dos homens, cuja falência era visível, e cabia aos artistas, ainda que fosse somente como protesto contra o "escandaloso estado de coisas", assegurar "a suprema vitória de tudo que vem do sistema feminino no mundo em oposição ao sistema masculino". ${ }^{43}$

Tanto em Nadja (1928), quanto em L'Amour Fou (1937) e, por fim, chegado ao sucesso de sua busca por esse amor em Arcane 17 (1944), Breton trabalha a ideia de um amor que fosse capaz de unir os amantes de forma que saíssem da sua própria realidade, tornando-se somente um ser único, confundidos em suas individualidades: "[...] todo ser humano foi jogado na vida a procura de um ser de outro sexo, e um só, que combine com ele sob todos os aspectos [...] um único bloco de luz." 44 O momento do encontro é o momento da fusão total, unidade integral, orgânica e psíquica. André Breton atualiza, assim, a visão platônica sobre a androginia, em que o homem está condenado a conhecer a mulher que é sua metade perdida, destinada a ele desde o nascimento e que será amada por ele até o dia de sua morte. "Amor, único amor que existe [...], sempre adorei a tua sombra, a tua sombra mortal." ${ }^{45}$ E para André Breton, assim como a mulher é etimologicamente o símbolo do homem, também o casal andrógino que formam pelo amor constitui uma plenitude que é a "recriação, a recolocação perpétua do mundo num só e único ser [...] capaz de conseguir [...], com seus mil e um raios, o avanço do mundo". ${ }^{46} \mathrm{~A}$ mulher seria a chave do cosmo.

Parece-me que o que se disse até aqui já foi suficiente para percebermos que convém certa parcialidade para não cairmos numa armadilha e nos iludirmos à primeira vista com um possível 'feminismo' dos surrealistas ou com uma possível declaração de apreço à androginia que favoreça a união homossexual. A maior experiência do Surrealismo é a descoberta da alteridade, é verdade. O Surrealismo valorizou e atraiu a atenção para tudo o que o 'chamado à ordem', católico ou burguês, havia reprimido - o erótico, o bizarro, a substância inconsciente da atividade mental, a magia e o mito, numa aproximação direta com a psicanálise freudiana.

824 Estudos Feministas, Florianópolis, 22(3): 815-837, setembro-dezembro/2014 
47 Briony FER, 1998, p. 172.

${ }^{48}$ É comum, entre historiadores da arte, afirmar que o Surrealismo foi o movimento artístico, até então, que mais teve mulheres em seus campos de atuação, seja na poesia, nas artes, nas pesquisas ou no ensaio.

49 FER, 1998, 171.

50 Simone de BEUVOIR, 1970, p. 276-284.

51 BEUVOIR, 282.
O tema da sexualidade, tema central de suas preocupações, chega a ser bastante abrangente em suas implicações políticas. E não se tratava apenas de questionar a 'realidade', mas também de questionar a forma pela qual ela era normalmente representada. ${ }^{47}$

Portanto, a valorização do 'feminino' que aparece no substrato do Surrealismo tem como maior função o combate ao racionalismo do século anterior, visto como moralmente falido. A mulher, ligada à loucura, à histeria e ao primitivo, era a alteridade que os surrealistas procuravam. Assim, não somente aceitavam a mulher em seu meio, ${ }^{48}$ mas ainda aspiravam e celebravam o lado 'feminino' da sua própria personalidade que havia sido reprimido. A fantasia, portanto, não era somente sobre a feminilidade, mas também sobre os desejos dos homens e sobre a masculinidade. A mulher na estética surrealista, além de musa do artista na maior parte das vezes, "mais do que uma realidade, presença no tempo e no espaço da experiência histórica, ela é uma 'metáfora". 49 Simone de Beauvoir, em O Segundo Sexo, afirma que, apesar do abismo entre o tratamento dado à mulher pelos surrealistas e o dos pensadores católicos ou das ciências médicas, as quais convergiam para a defesa do papel de mãe, seja espiritual ou biológica, há analogias. No universo poético de Breton, a mulher "é um elemento de perturbação; ela arranca o homem do sono da imanência; boca, chave, porta, ponte, é a Beatriz iniciando Dante no além". Nadja, de Breton, a mais extraordinária das feiticeiras, é "uma alma errante", que se conduz na vida "de uma maneira singular, só se baseando na pura intuição e participando sem cessar do prodígio"; desdenha as leis da razão e acaba num hospício. Ela malogra em desempenhar seu papel feminino. Vidente, pítia, inspirada, ela situa-se próxima de criaturas irreais; abre as portas do mundo irreal, mas é incapaz de dá-lo porque não poderia dar-se ela própria. "Essa mulher única, a um tempo carnal e artificial, natural e humana, tem o mesmo sortilégio que os outros objetos que os surrealistas amam: é semelhante à colher sapato, à mesa-lobo, à pedra-deaçúcar..." 50

Mas, principalmente, a mulher é para os surrealistas a beleza, na análise de Simone de Beauvoir. E a beleza não é para Breton uma ideia que se contempla, e sim uma realidade que se revela - portanto não existe - senão através da paixão. A beleza confunde-se com a "noite profunda do conhecimento"; é a verdade, a eternidade, o absoluto; não é um espaço temporal e contingente do mundo que a mulher liberta, é sua essência necessária. ${ }^{51}$ Numa perspectiva exclusivamente poética, é exclusivamente como poesia, portanto como outro que a mulher é nela encarnada. Ela é a poesia em si, no imediato, isto é, para o homem. Breton 
${ }^{52}$ BEUVOIR , p. 283.

${ }^{53}$ Estrella de DIEGO, 1992.

${ }^{54}$ DIEGO, 1992, p. 132.

${ }^{55}$ DIEGO, 1992, p. 24

${ }^{56}$ OVIDIO, 2010, p. 124.

57 Théophile GAUTIER, 2008, p. 333. não fala da mulher enquanto sujeito. Nunca evoca a imagem da mulher má; a mulher só lhe interessa porque é uma "boca" privilegiada. Profundamente ancorada na natureza, bem próxima da Terra, ela se apresenta também como a chave do além. ${ }^{52}$

Para bem da verdade, a figura mítica do andrógino primitivo esconde, no fundo, uma primazia do princípio masculino. Como vimos acima, o mito do andrógino serviu para simbolizar um estado de completude no qual o homem (e o termo homem não em realidade como uma referência ao gênero humano em seu conjunto, mas como uma alusão especial ao gênero masculino) acharia sua expressão total. Segundo Estrella de Diego, ${ }^{53}$ ainda que o paradigma implique numa unidade entre os sexos, a figura clássica de gênero outorga com frequência um papel subordinado do feminino ao masculino. As mulheres, diz a ensaísta, "han pasado su historia prendidas del cuerpo, no solo sometiéndolo a cambios violentos a medida que variaba la moda, sino a cambios estructurales en sus propios deseos." Já o corpo masculino - ao menos nas classes médias - "ha sido un cuerpo estático, el mismo cuerpo durante siglos." ${ }^{44}$ Podemos ver então, "no la búsqueda de un otro, sino una búsqueda de una complementariedad interna. La conciliación de los opuestos, el ser andrógino." A imagem do andrógino, assim, "simboliza la melancolía de la separación y la desesperación del reencuentro o, dicho de otro modo, se refiere a la circulación del deseo, nunca del placer." 55 Podemos aqui recordar Hermafrodito de Ovídio. É a figura feminina de Salmacis, que, depois de rogar para que nunca seja separada de seu objeto de desejo, perde sua própria identidade, submetida ao corpo de Hermafrodito. Por outro lado, o menino do mito nasceu bonito e transformou-se em hermafrodita, como castigo, por ter se unido à ninfa. Hermafrodito, aflito e envergonhado, amaldiçoou o lago, de forma a que todos que se banhasse nele se transformassem também como ele. "Quem quer que nessa fonte entre homem saia semi-varão e, logo ao tocá-la, efemine-se."56

Em Mademoiselle de Maupin, de Gautier, que citamos acima, a certa altura do romance a personagem reflete sobre sua condição de "terceiro sexo", que ainda não tem nome.

Minha quimera seria ter os dois sexos, por turno, para satisfazer esta dupla natureza: homem hoje, mulher amanhã. Reservaria para meus amantes a lânguida ternura, meus modos submissos e sacrificados, minhas suaves carícias, meus suspiros tênues e exaltados, tudo o que de gata e de mulher tem minha pessoa; logo, para minhas amadas, seria atrevido, audaz, apaixonado, de modos triunfantes, o chapéu sobre a orelha, porte de capitão e aventureiro. ${ }^{57}$ 


\section{O casal amoroso}

${ }^{58}$ Frida KAHLO, 2005, p. 60.

${ }^{59}$ Ferdinand ALQUIÉ, 1977, p. 92.

\author{
Diego principio \\ Diego constructor \\ Diego mi niño \\ Diego mi novio \\ Diego pintor \\ Diego mi amante \\ Diego 'mi esposo' \\ Diego mi amigo \\ Diego mi padre \\ Diego mi hijo \\ Diego $=$ Yo $=$ Diego Universo \\ Diversidade en la 'unidade'. 58
}

C'est de l'amour que les surréalistes attendent la grande révélation. ${ }^{59}$

Na biblioteca de Frida, foram encontrados exemplares de O banquete, de Platão, de Mademoiselle de Maupin e da revista surrealista Minotaure com o artigo de Béguin. Frida, embora negasse por diversas vezes seus vínculos como o surrealismo, ${ }^{60}$ fora celebrada por Breton. ${ }^{61}$ Há ainda informações de que ela teria lido escritores como Balzac e Joséphin Péladan, ${ }^{62}$ materiais que circulavam à época e que devem ter ajudado a confirmar sua imaginação sobre a androginia.

Contudo, a abordagem da androginia na obra de Frida Kahlo ultrapassa o reino das ideias e entra na vida de forma clara e às vezes contundente a expressar sua própria história. Patricia Mayayo pergunta-se, ao final de sua reflexão sobre a fusão andrógina que aparece em algumas obras da artista, se não implicaria a renúncia da diferença, a perda da identidade em favor da subordinação à figura masculina. Nesse caso, o ideal de androginia se representaria, na imaginação de Frida, talvez, não só, ou nem tanto, como um processo de fusão mútua, mas também como uma dissolução da própria identidade na identidade do amado, "como una integración entre Yo en un Outro que se concibe como imagen del universo, como trasunto de la totalidad divina". ${ }^{63} \mathrm{Em}$ seu Diário nos deparamos com diversas passagens em que Frida faz de si uma dissolução total e uma entrega absoluta a seu Diego.

\footnotetext{
Diego.

Verdad es, muy grande, que yo No quisiera, ni hablar, ni dormir, ni oir, ni querer. Sentirme encerrada, sin miedo a la sangre, sin tiempo ni magia, dentro de tu mismo miedo. y dentro tu gran angustia, $y$
} 


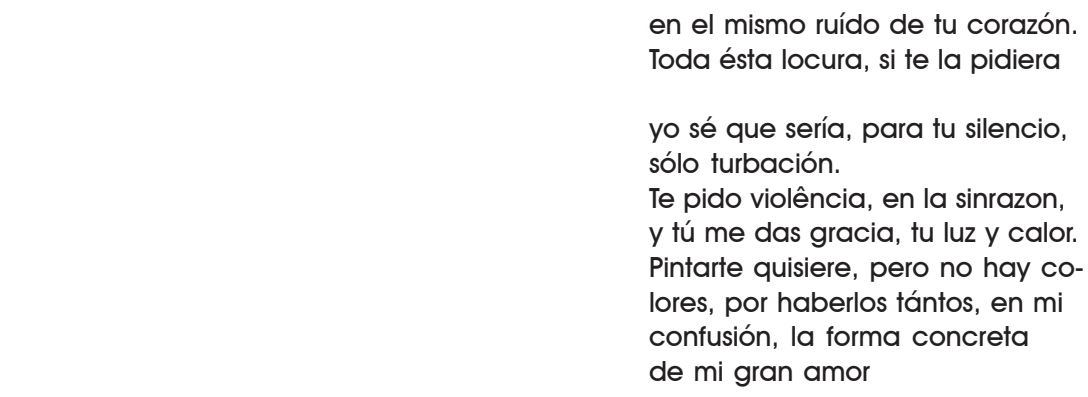

${ }^{64}$ MAYAYO, 2008, p. 248.

${ }^{65}$ KAHLO, 2005, p.145.

${ }^{66}$ Hayden HERRERA, 2011 , p. 378.
Como se vê, a visão de androginia de Frida encontrase envolta em contradições: a personagem travestida e desafiante, que reinterpreta o modelo europeu de la garçonne, que assimila a transformação mais radical dos padrões de subjetividade femininas com a positivação da imagem do lesbianismo, opõe-se à esposa devota, que se anula na fusão com o ser amado. ${ }^{64}$ Depois de longos anos de vida amorosa tumultuosa, nos últimos dias de vida ainda registra em seu: "Amo a Diego más que a mi misma". ${ }^{65}$ Imersa no difícil processo de negociação entre modelos contrapostos, Frida se apresenta, assim, com a mesma ambiguidade de muitas das mulheres de sua época, entre o desejo de ser esposa e mãe (lembramos o sofrimento dela nas tentativas de gravidez) e o de transgredir as condutas femininas para tentar escapar dos papéis de gênero tradicionais.

Hayden Herrera ${ }^{66}$ sugere que o Autorretrato con trenza (1941) pode ser visto como uma contraparte, uma volta atrás, ao Autorretato de pelona (1940) que analisamos acima. O observador imagina que os cabelos que estavam espalhados pelo chão, agora, foram recolhidos, trançados em formato de pretzel e arranjados no topo da cabeça de Frida. Recolocar os cabelos pode ser a reafirmação da feminilidade que ela havia negado para magoar Diego, diz Herrera. Não são poucos os autorretratos que expressam o grande amor de Frida pelo marido, a necessidade que ela sentia dele e a conexão entre os dois de diferentes maneiras. No Autorretrato como tehuana (1943), o amor obsessivo de Frida pelo marido indomável fez com que ela aprisionasse a imagem de Diego na própria testa. Retrato doble de Diego y yo 1929-1944 (1944), analisado acima, fora um presente de aniversário dela para ele. Frida, encapsulando sua ânsia de unir-se a Diego - literalmente, de ser Diego, fundindo sua própria identidade à dele -, pintou os dois formando uma única cabeça. Em Diego y Yo (1949), o desespero de Frida com os flertes e namoros de Rivera é quase histérico. Novamente, o retrato do marido está alojado na testa de Frida, e ela parece estrangular-se no redemoinho de seus próprios cabelos. Quando pintou EI 
${ }^{67}$ HERRERA, 2011 , p. 437.

${ }^{68}$ HERRERA, 2011 , p. 453.

${ }^{69}$ NERY, 2004, p. 19.

${ }^{70}$ NERY, 1984, p. 194-196.

${ }^{71}$ Davi ARRIGUCI JR., 2000, p. 109.

${ }^{72}$ NERY, 1984, p. 152-162. abrazo de amor entre el universo, la tierra (México), yo, Diego y el señor Xólotl (1949), Frida ainda chora, mas o relacionamento parece ter encontrado alguma resolução. Diego aparece como um bebezão deitado no colo maternal de Frida. ${ }^{67}$ Dada à intensidade do amor carnal de Frida por Diego, não surpreende que as infidelidades sexuais do marido a machucassem tanto. Para se proteger, ela assumiu a postura de mãe indulgente. Frida é uma espécie de mãeterra mexicana, e Diego é seu filho recém-nascido. ${ }^{68}$

Encontramos operação artística e sentido simbólico diferentes nos casais de Ismael Nery. No 'par amoroso' as duas figuras fundem-se num abraço que embaralha as personagens. "Corpos que se entrelaçam, entrecruzam, entredevoram, renascendo em uma outra forma."69 Fusão demonstrada e desejada também em versos como "Eu sou o marido e a mulher" do poema $\mathrm{Eu}$. Reconhecemos Ismael e Adalgisa entre os amantes representados iconograficamente, mas descobrimos que funcionam apenas como figuras alegóricas e nunca como representação de um estado de ânimo do casal Ismael / Adalgisa. Os críticos afirmam que o artista brasileiro fazia do casal humano o centro de seu universo plástico, inclusive quando o assunto era erótico ou sexual. ${ }^{70}$ Para o artista brasileiro, na abstração do tempo e do espaço, não havia lugar para divisões entre sexo, erotismo e castidade, tudo era voltado para uma mesma experiência mística. Seu projeto de desintegração do corpo pictórico encerrava o desejo de encontrar a essência da forma divina como energia pura, o que o levou a criar o sistema filosófico que denominou Essencialismo, uma espécie de catolicismo reformado, com base no cristianismo primitivo, a partir do Evangelho de São João, do pensamento de Santo Agostinho e de Santo Tomás de Aquino, da leitura de Nietzsche e dos pré-socráticos, para ser vivido no dia a dia, concretamente, e que aceitava aspectos do Comunismo e do Surrealismo, ambos vistos como "o evangelho da nova era, a ponte da libertação". ${ }^{71}$

No Álbum de 1984, que comemora os 50 anos da morte de Ismael, e que reúne depoimentos de amigos e contemporâneos, há uma seção que se intitulou $O$ par amoroso: do colóquio à fusão. ${ }^{72}$ Dos 21 quadros da série, em sete deles o casal apresenta-se com certa organicidade, estando as duas personagens ombreadas e sexualmente definidas, numa postura de confabulação. De resto, dois terços da série, a iconografia produz um movimento que sobrepõe, transpassa, embaralha e mescla cabeça, rosto, membros, órgãos genitais. O resultado é a fusão de dois corpos, masculino e feminino, a formar o par amoroso, integrado ao cosmo, o que Ismael resolve plasticamente envolvendo as figuras em extensões sombreadas ou transparências que 
minimizam o contorno. Nestes quadros, o artista enfatiza a procura pela unidade primordial, como se quisesse traduzir plasticamente o momento do 'reencontro' do Andrógino de $O$ Banquete de Platão, ou resolver pictoricamente o preceito de André Breton: a complementariedade dos dois amantes lhes permite engendrar o cosmos, como este os engendra.

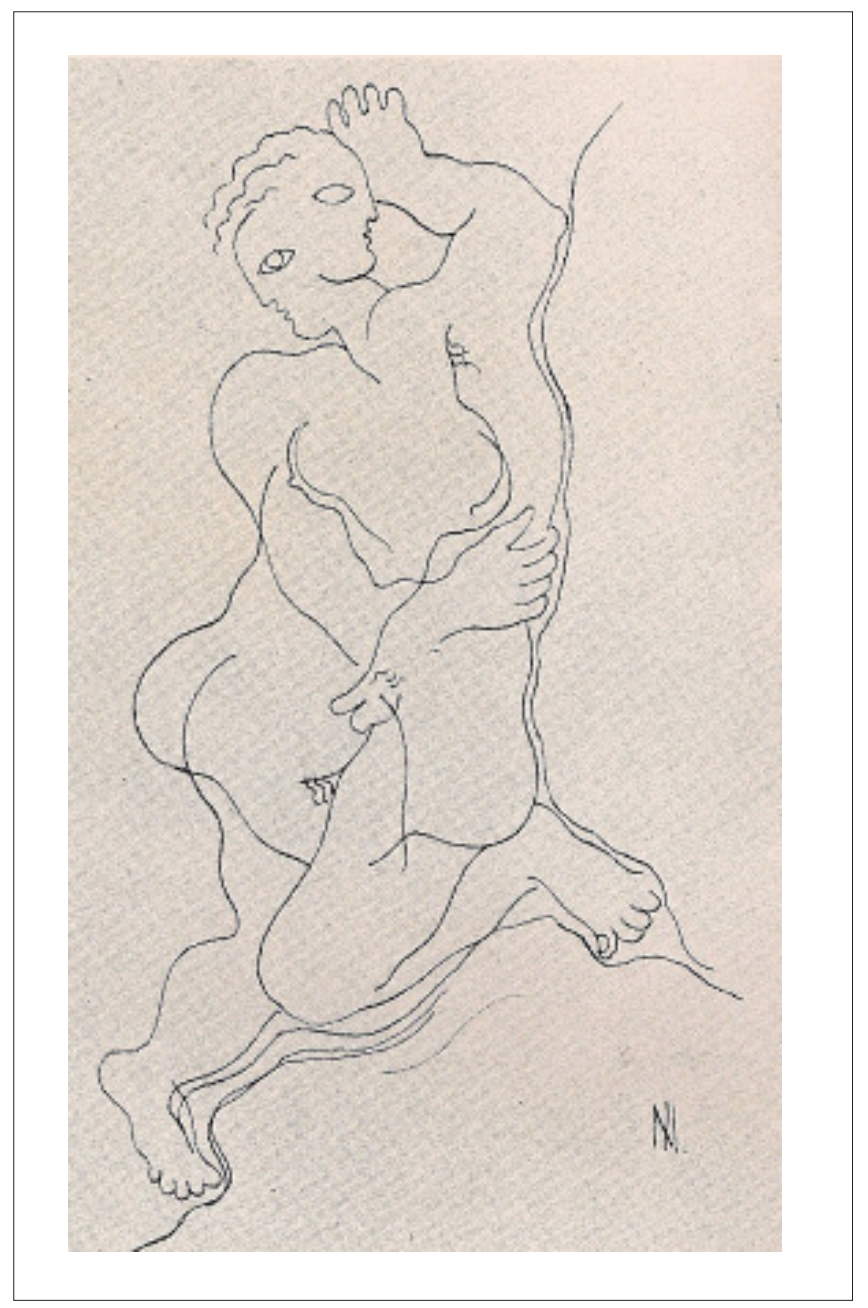

E se na série O par amoroso: do colóquio à fusão vemos Ismael resolver plasticamente o abraço amoroso que integra os amantes em uma só figura, somos surpreendidos quando nos deparamos com o quadro Pecado Original. Nele, vemos o momento da separação, da desintegração, entre Adão e Eva. No quadro Pecado Original, o movimento 
${ }^{73}$ NERY. Pecado Original, s/d. crayon e aquarela s/papel, 26,5x17,2 cm, col. Chaim José Hamer, SP. In: NERY, 1984, p. 161 plástico não se dá em sístole, para dentro, como nos quadros de 'encontro', em que os casais se abraçam e se integram. Em Pecado original, ${ }^{73}$ vemos um movimento em diástole, para fora, em que as figuras da mulher, do homem e da árvore antropomórfica, com os pés e membros inferiores das três figuras ainda unidos, porém, em posição de 'avançar'. Eva agarrada às costas de Adão, o quadro retrata os segundos que antecedem a queda do homem, a separação com a natureza e a maldição da dominação feminina.

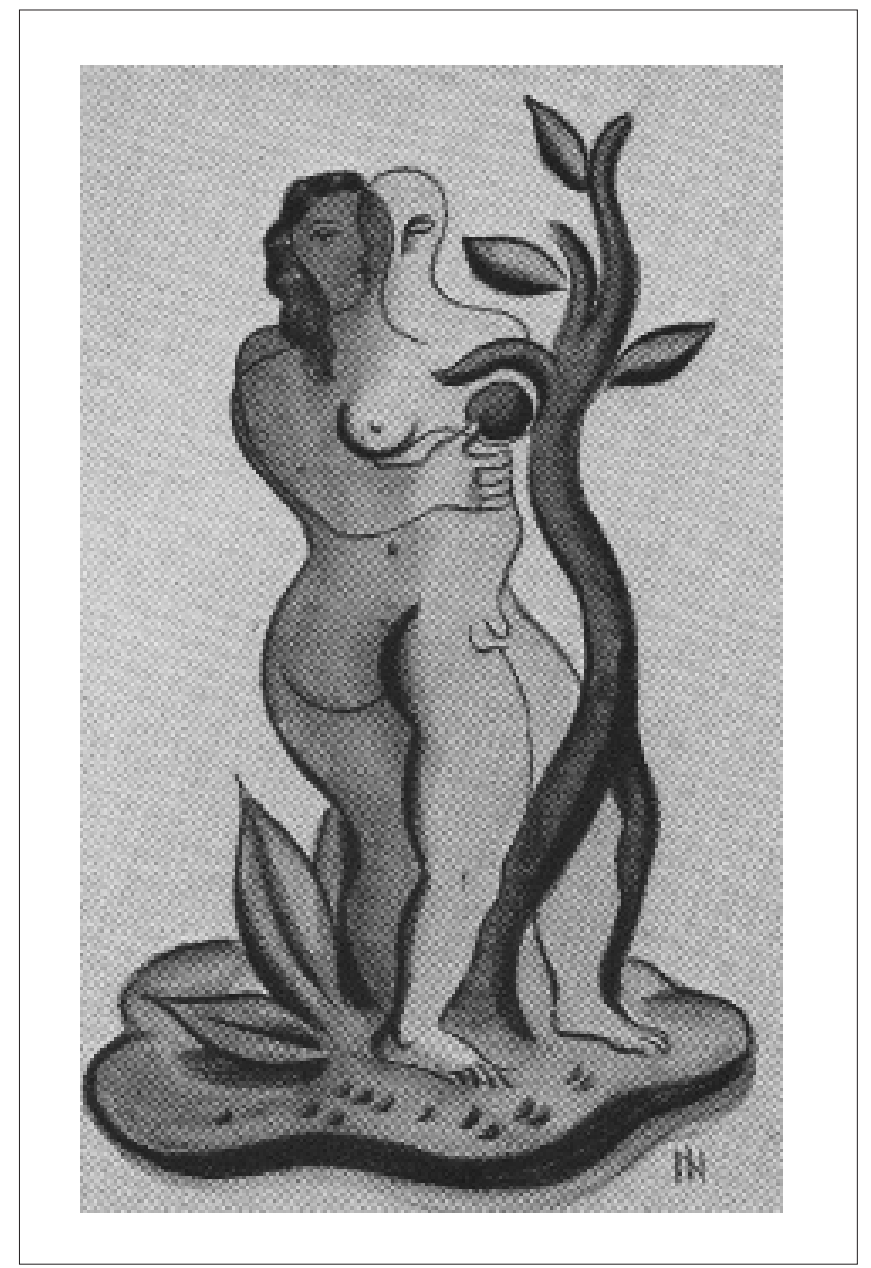

No poema de 1932, Ismael/lsmaela se lê:

A minha irmã é minha edição feminina e meu castigo. 
${ }^{74}$ NERY, 2000, p. 74.

${ }^{75}$ Apud, NERY, 2000, p. 61
${ }^{76}$ Não temos referências concretas sobre as leituras que povoaram a imaginação de Ismael. O artista não deixou biblioteca e os contemporâneos dizem que Ele era leitor assíduo da Bíblia, desde a infância, e que tinha grande interesse por tratados de anatomia.

${ }^{77}$ MAYAYO, 2008, p. 248.
Dá a todos o que eu nunca de mulher alguma recebi.

Se eu não soubesse que sou também o seu castigo

Há muito tempo que seria fratricida ou suicida. ${ }^{74}$

O texto literário confirma o texło pictórico. Na análise de Sant'Anna, ${ }^{75}$ há uma "edição feminina" colada a seu ser masculino, como no quadro Andrógino. No substrato da duplicidade e da linguagem religiosa, a metáfora possível do primeiro casal, Adão e Eva, presente na sua obra. Ismael/ Ismaela no texto, assim como Ismael/Adalgisa na pintura, falam da fenda e de uma colagem, da unidade perdida (re)inscrita.

No Gênesis, que Ismael conhecia muito bem, ${ }^{76} \mathrm{a}$ origem de toda nostalgia está na perda da androginia como resultado da Queda: a separação que retira o elemento feminino do corpo uno e o automatiza resulta numa degradação tanto na ordem cósmica, quanto na ordem física. O homem primordial foi o Adão em sua totalidade, bissexuado, inteiro em sua essência, que, depois de uma queda, um sono ou um duelo com os deuses teria sido dividido em dois seres - homem e mulher - ficando assim a natureza humana condenada a uma vida incompleta e de insatisfação, até o momento em que os dois se unem novamente em gozo e plenitude atingindo outra vez o estado de andrógino primordial.

\section{Tensão e harmonização}

À guisa de conclusão, deixamos como hipótese a suposição de que a androginia aparece na obra dos dois artistas com sentidos pessoais próprios, correlacionados à vida e a arte de cada um, a despeito de fontes culturais comuns. Frida foi mais narrativa, mais autobiográfica, fez da androginia expressão de suas experiências. Ismael, mais voltado para experiências místicas, os retratos aparecem como figuras alegóricas nas quais se percebem a busca de um ideal, na beleza da forma ou no significado do intencional que a figura carrega. Assim, suas figuras andróginas podem aparecer não como retratos de pessoas, mas como retratos de funções.

Na obra de Frida Kahlo, como vimos acima "cabe la posibilidad, sin embargo, de que esa voluntad de fusión se refiera a su siempre adorado Diego". ${ }^{77}$ Mas Frida estava longe de ser uma vítima passiva da luxúria do marido. Frida se contrapunha à infidelidade de Diego encetando seus romances extraconjugais. Frida acreditava que o que se chamava de la raza - pessoas menos dominadas pelas exigências da civilização - tinha menos inibições quanto à 
78 HERRERA, 2011 , p. 446.

79 HERRERA, 2011 , p. 448.

${ }^{80}$ Antônio BENTO, 1973, p. 58.

sexualidade e, uma vez que ela queria ser primitivista em seu comportamento, fazia questão de ser franca em matéria de sexo. ${ }^{78}$ Frida ficou mais masculina na década de 1940, pintando ainda mais forte seu bigode de Zapata, mas sempre houve um aspecto andrógino em Frida e Diego: ambos se sentiam atraídos por aquilo que viam do próprio sexo no parceiro. Ele adorava a puerilidade de Frida e amava seu bigode de "Zapata" - ficou furioso quando ela o raspou. Ela adorava a qualidade suave e vulnerável do marido; adorava seus seios de homem gordo. ${ }^{79}$

Ismael Nery, por sua vez, conforme ressalta Antônio Bento, era favorável à moda única para homens e mulheres. A indumentária de suas figuras plásticas tinha um caráter atemporal, tanto podendo ser a túnica da antiguidade como uma veste renascentista ou simples blusa proletária. ${ }^{80}$ Ele queria liberar suas figuras de qualquer contingência histórica, a fim de que não passassem de meras figuras, nada mais que sínteses plásticas formais. Os contemporâneos afirmam que Ismael, na vida cotidiana era um homem muito elegante, desenhava suas roupas e as de Adalgisa, gostava de dançar e dançar, e praticava o remo. Ismael era um dândi. Denise Mattar considera que ele se vestia com trajes teatrais e informa que há uma foto de Ismael, vestido de mulher, ao lado de Mendes. "Nery jamais teve medo de realizar obras sobre seu duplo feminino." 81

Mas essas características pessoais estão longe de contribuir para nos informar sobre a androginia que aparece na sua arte. Luiz Munari, ao analisar a série de casais pintados por Ismael Nery, diz que se poderia pensar que o artista quisesse indicar o tema do hermafroditismo, mas desconfia de que fazer alusão à (bi)sexualidade pode parecer que ele pretendesse potencializar o prazer sexual, o que seria muito pouco e não corresponderia às suas preocupações que são místicas, por tudo que se vê na obra e no pensamento do artista. Para Munari, o projeto de Nery era personificar o amor, na medida em que não mostra apenas a relação, mas o amor como fusão de espírito dos amantes, que pode representar também a fusão de seus corpos. ${ }^{82}$

Ismael faz da pintura e da poesia a condição para expressar suas ideias. A diferenciação entre masculino e feminino, calcada numa bipolarização, encontra na sua obra uma harmonização numa síntese de resolução artística. Quando Ismael faz uso de sua própria imagem e a da esposa, opera propriamente no campo da abstração, pintando não a reprodução do casal Ismael/Adalgisa, ${ }^{83}$ mas um simulacro para especular sobre seu sistema filosófico. $O$ artista brasileiro julgava a arte um ponto muito elevado na hierarquia espiritual, e o artista, uma divindade criadora, em ressonância, talvez, com Kandisky. Em 1912, o artista 
${ }^{84}$ Vasili KANDINSKY, 2008, p. 27 29.

\begin{abstract}
${ }^{85} \mathrm{~A}$ amizade que Ismael fizera com Chagal e o diálogo que estabelecera com André Breton, em Paris, na sua segunda viagem à Europa, em 1927, o influenciaram definitivamente, embora não se possa dizer que tenha praticado um surrealismo ortodoxo.
\end{abstract}

${ }^{86}$ NERY, 2000, p. 73. russo publicara Do espiritual na arte, obra que tivera grande repercussão no meio artístico.

Para Kandinsky, a arte deve mostrar o mundo invisível, e o artista, portanto, um visionário, que vê e ensina, que carrega o fardo da humanidade, que gostaria de abandoná-lo, mas não pode, pois tinha a missão de despertar a Europa, de darIhe esperança e novos rumos, depois de seu longo período materialista, de falta de fé, de meta e de sentido. ${ }^{84}$ No poema $E u$, já citado, Ismael escreve: "Eu sou o sucessor de Jesus Cristo / Encarregado dos sentidos do universo". A pecha de narcisista que muitos críticos enfatizam em relação ao seu caráter pode ter sido instigada pelas suas declarações explícitas de autorreconhecimento de seus poderes intelectuais, místicos e visionários. Um narcisismo que caminha para a angústia e o aniquilamento, e que expressa seu desespero na androginia, na reunião carnal e espiritual, na fusão das formas e das disparidades. "Eu sou o que não existe entre o que existe / Eu sou tudo sem ser coisa alguma." Como artista místico, que harmonizava sua qualidade de visionário com o de artífice, Ismael ressoa muito mais que Frida Kahlo as concepções dos surrealistas ${ }^{85}$ quanto à condição da mulher, como se percebe explicitamente no seu poema A noiva do poeta (1932): "A minha noiva magnífica só existe / Na minha imaginação". Ismael potencializa seu poder de criação, fazendo coincidir suas criaturas com ele mesmo. No poema a Musa decadente (1932), podemos escutar ecos do que se falou acima sobre Breton.

$$
\begin{aligned}
& \text { Quem teria descoberto sem mim } \\
& \text { Que tua nuca pálida e que tuas pernas finas } \\
& \text { Que tua voz rouca e que teus olhos mortos } \\
& \text { Que teus cabelos ralos e que teu riso amarelo } \\
& \text { São coisas belas, mesmo muito belas? } \\
& \text { Tu és a minha musa e meu elogio vivo }
\end{aligned}
$$

A beleza não pertence à musa; constitui-se a partir da palavra do poeta que tem o poder inclusive de subverter o feio; de divindade inspiradora e fonte originária e absoluta da poesia, a musa passa à condição de resultante poética.

Em Frida, o andrógino oscila entre o espiritual e o político, entre o mito e a transgressão, dentro das condições pessoais e dos limites de sua época. Ismael usou a arte para configurar suas preocupações religiosas e espirituais. Se o conflito entre masculino e feminino fica patente e até gritante na obra de Frida, em Ismael, a relação de gênero sequer é um problema. Quando Frida mistura sua imagem com a de Diego, ela refere-se a um relacionamento biográfico que varia conforme seu estado de ânimo. É uma composição repleta de tensão e ambiguidade. Ao mostrare em composições que misturam aspectos masculinos e

834 Estudos Feministas, Florianópolis, 22(3): 815-837, setembro-dezembro/2014 
${ }^{87}$ NERY, 1984, p. 194-196.

${ }^{88}$ Ângelo GUIDO, 1969, p. 84.

${ }^{89}$ Jean BAUDRILLARD, 1981 p. 17. femininos na sua própria figura, ela mostra imagens próximas dos modelos andróginos dos anos vinte e trinta, numa função política importante, na tentativa de subverter e ampliar as categorias de gênero estabelecidas.

Ismael, por sua vez, numa arte transcendente, estreitava laços entre pintura e religião, entre estética e misticismo; via o corpo como molde da alma; baseado no tomismo acreditava numa unidade divina na qual toda a humanidade e cada um faziam parte dela, confrontada constantemente com o criador. ${ }^{87} \mathrm{O}$ casal, ou o "sexo artístico por excelência", expressa um amor sublime e harmonioso; uma fusão amorosa que pertence ao mundo das ideias. $O$ andrógino de Ismael junta-se, talvez, a Serafita de Honoré de Balzac, um ser quase celeste que, sob os olhos apaixonados de Minna e Wilfrid, transforma-se em serafim e sobe aos céus. O andrógino de Balzac, como ilustração da doutrina de Swedenborg, não é um ser que possa viver na Terra. O Cristo andrógino de Ismael talvez se sinta à vontade junto do Cristo da Santa Ceia, de Leonardo da Vinci. O tipo andrógino em figuras nas quais Leonardo da Vinci quis associar a beleza natural à beleza espiritual, ou identificar a luz interior das figuras, foi resultado de uma procura consciente e lúcida da visão do significado que se encerra no mito do Andrógino. ${ }^{88}$

Uma fusão impossível? Talvez, enquanto ficarmos no discurso sobre a sexualidade, que pertence à ordem cultural, social e biológica: analisa, conhece, explica, nomeia, protege, encaminha, organiza, divide, hierarquiza, discrimina e condena. Mais interessante seria ficarmos com a perspectiva da sedução, nos diz Baudrillard, que pertence à ordem do "simulacro e do ritual", encontra-se fora das oposições masculino / feminino e cria outras relações. "Solo la sedución quiebra la sexualidade distinta de los cuerpos y la economia fálica inevitable que resulta." ${ }^{9}$

\section{Referências}

ADDINGTON, Symonds. A Problem in Modern Ethic. An inquiry into the phenomenon of sexual inversión. London. Cópia digitalizada pela Amazon, 1891.

ALQUIÉ, Ferdinand. Philosophie du surréalisme. Paris: Flammarion, 1977.

ARAGON, Louis. O camponês de Paris. Trad. Flávia Nascimento. Rio de Janeiro: Imago, 1996.

ARRIGUCI JR., Davi. O cacto e as ruínas. São Paulo: Ed. 34, 2000.

BALZAC, Honoré de. Serafita. Trad. Álvaro Ribeiro. Lisboa: Ésquilo, 2006. 
BAUDRILLARD, Jean. De La sedución. Trad. Elena Benarroch. Madrid: Ediciones Cátedra, 1981.

BÉGUIN, Albert. L'androgyne. Minotaure, n. 11, primavera de 1938. p. 10-13.

BENTO, Antônio. Ismael Nery. São Paulo: Gráficos, 1973.

BEUVOIR, Simone de. Breton ou a Poesia. In: O Segundo Sexo. 4. ed. Trad. Sérgio Milliet. São Paulo: Difusão Europeia do Livro, 1970.

BRETON, André. Nadja. Trad. Ivo Barroso. Rio de Janeiro: Imago, 1999.

. O Amor Louco. Trad. Luiza N. Jorge. Lisboa: Editorial Estampa, 1971.

. Arcano17. Trad. Maria T. de Freitas e Roasa M. Boaventura. São Paulo: Brasiliense, 1986.

CARPENTER, Edward. Intermediate Types among Primitive Folk (1911/1919). London: The Echo Library, 2007.

DIEGO, Estrella de. El andrógino sexuado. Madrid: Visor, 1992.

ELIADE, Mircea. Mefistófiles e o Andrógino. Trad. I. C. Benedetti. São Paulo: Martins Fontes, 1999.

FER, Briony; BATCHELT, David; WOOD, Paul. Realismo, Racionalismo, Surrealismo. Trad. Cristina Fino. São Paulo: Cosac \& Naify, 1998.

FLORES, Maria Bernardete Ramos. Tecnologia e estética do racismo. Chapecó/SC: Argos, 2007.

GARCÍA, Francisco V. "La imposible fusión. Claves para uma genealogia del cuerpo andrógino". In: SOLís, Diego Romero de, MUÑOZ, Juan Bosco Días-Urmeneta; LLORET, Jorge López. (Org.). Variaciones sobre el cuerpo.Sevilha: Universidad de Sevilha, 1999. p. 217-235.

GAUTIER, Théophile. Mademoiselle de Maupin. Trad. Carlos de Arce. Barcelona, DEBOLSILLO, 2008.

GUIDO, Ângelo. Símbolos e mitos na pintura de Leonardo Da Vinci. Porto Alegre: Sulinas, 1969.

HERRERA, Hayden. Frida. A biografia de Frida Kahlo. Trad. Renato Marques. São Paulo: Globo, 2011.

HUYSMANS, Joris-Karl. Às avessas. Trad. José P. Pais. São Paulo: Cia das Letras, 2011 [1884].

KAHLO, Frida. The diary of Frida Kahlo. An intimate self-protrait. (1944-1954). Essay and Commentaries by S. M. Lowe. New York: ABRAMS, 2005.

KANDINSKY, Vasili. De lo espiritual en el arte. Trad. G. Dieterich. Buenos Aires: Paidós, 2008.

LIBIS, Jean. El mito del andrógino. Trad. de Maria Tabuyo y Agustín López. Madri: Ediciones Siruela S.A, 2001.

LOZANO, Luis-Martín. "Frida Kahlo: Uma relectura para conocer el universo estético de la pintora". In: Álbum Frida Kahlo. Ciudad de Mexico: Oceano; Landucci, 2007. p. 18-206. 
MAYAYO, Patricia. Frida Kahlo: Contra el Mito. Madri: Ediciones Cátedra, 2008.

MICELI, Sergio. Imagens negociadas. São Paulo, Companhia das Letras, 1996.

MUNARI, Luiz A. S. Ismael Nery. Pinturas e Fábulas. São Paulo: USP, 1984. Dissertação (Mestrado em História) Faculdade de Filosofia, Letras e Ciências Humanas, Universidade de São Paulo, São Paulo.

NERY, Ismael. Álbum. Ismael Nery. Rio de Janeiro: Curadorial Denise Mattar, 2004.

Álbum. Ismael Nery 50 anos depois. Curadoria de Aracy Amaral. São Paulo: AC-USP, 1984.

. Álbum - Ismael Nery 100 anos, a poética de um mito. Curadoria Denise Mattar. São Paulo: Centro Cultural Banco do Brasil; Fundação Armando Álvares Penteado, 2000.

OVIDIO. Metamorfoses. Trad. Raimundo Nonato Barbosa de Carvalho. São Paulo: USP, 2010.

PÉLADAN, Joséphin. Dell andrógino. Teoria amorosa - Teoria plástica. Trad. V. Bondois e G. Ferrero. Milano: LibriPerduti, 2011 [1910].

PESSOA, Fernando. Portugal, sebastianismo e Quinto Império. Pref., intr., org. de A. Quadros. Lisboa: Europa-América, 1986.

PLATÃO. O Banquete: ou, Do amor. Trad: J Cavalcante de Souza. 8. ed. Rio de Janeiro: Bertrand Brasil, 1997.

RADO, Lisa. The modern androgyne imagination. Virginia/ EU: The University Press of Virginia, 2000.

WEININGER, Otto. Sexe et caractere (1903). Trad. par Daniel Renaud. Lausane: L'Age d'Home, 1975.

WESTERMARCK, Edward. The Origin and Development of Moral Ideas (1906). London: Macmillan, 2006.

[Recebido em março de 2013

e aceito para publicação em junho de 2013]

\begin{abstract}
Androgyny and Surrealism Regarding Frida and Ismael - Old Myths: Eternal Feminine Abstract: In the first decades of the twentieth century, the myth of the Androgyne returns as a promise of spiritual happiness. Among the Surrealists, the androgyny, along with the cult of the woman, worked as alterity, as appreciation of underground modernity. Androgyny appears in several works of Frida Kahlo in Mexico and in Ismael Nery, in Brazil, both with a surrealistic approach. In Frida, the myth oscillates between spiritual and political, between transgression and subjection, going to the lesbianism and the desire to invert the traditional gender roles to the dissolution of her own identity, submitted in love by her husband. In Ismael, the duplicity of his selfportraits and iconography of loving couples expresses the fusion of the sexes as part of the world of ideas. "Artistic sex par excellence," the myths appear more strongly in the art of Ismael Nery. Key Words: Androgyny; Surrealism; Frida Kahlo; Ismael Nery.
\end{abstract}

